\title{
Variation of right renal artery duplication with retroaortic left renal vein: a case report*
}

\author{
Ozan Turamanlar ${ }^{1}$, Ebru Ünlü', Muhsin Toktaş ${ }^{3}$, Erdal Horata $^{1}$, Ahmet Songur $^{1}$ \\ ${ }^{1}$ Department of Anatomy, Faculty of Medicine, Afyon Kocatepe University, Afyonkarabisar, Turkey \\ ${ }^{2}$ Department of Radiology, Faculty of Medicine, Afyon Kocatepe University, Afyonkarahisar, Turkey \\ ${ }^{3}$ Department of Anatomy, Faculty of Medicine, Turgut Özal University, Ankara, Turkey
}

\begin{abstract}
Variations of renal arteries and veins are of particular importance in the treatment of renal and renovascular conditions. Multiphase upper abdominal computed tomography of a 68-year-old male patient with renal cell carcinoma of right kidney revealed duplication of right renal artery and retroaortic left renal vein variation. Differential diagnosis should be made with great care in patients with renal neoplasms since variations may complicate diagnostic procedures. Here, we present a rare variation. Knowledge of variations accompanied by pathologies as in our case may be important as it can affect diagnostic and treatment procedures. The aim of this case report and literature review is to increase awareness about renal vascular variations among clinicians and oncologists who work in this field.
\end{abstract}

Keywords: retroaortic left renal vein; right renal artery duplication; variation

Anatomy 2015;9(2):91-93 @2015 Turkish Society of Anatomy and Clinical Anatomy (TSACA)

\section{Introduction}

Renal arteries originate from the abdominal aorta at the level of the intervertebral disc between the first and second lumbar vertebrae. Both of the renal veins are located anterior to the renal arteries. Left renal vein is the longer of the two and courses anterior to the abdominal aorta. ${ }^{[1]}$ Knowledge of renal vascular variations is important in several conditions including renal trauma, renal transplantation, renovascular hypertension, renal artery embolization, angioplasty or vascular reconstruction in congenital and acquired lesions, abdominal aortic aneurysm surgery, research and treatment concerning radical or conservative kidney surgery. ${ }^{[2]}$

\section{Case Report}

A 68-year-old male patient diagnosed with renal cell carcinoma of right kidney was admitted to Radiology Department of Afyon Kocatepe University Hospital.
Multiphasic upper abdominal computed tomography examination was performed using an 80-row detector CT (160 slice) scanner (Aquilion Prime, Toshiba Medical Systems, Nasu, Japan). Nonionic contrast agent (1.5 mL/kg) (iopromide-300; Ultravist, Schering, Berlin) was administered and automatically injected at a flow rate of $2 \mathrm{~mL} / \mathrm{s}$. An unenhanced CT scan was initially performed and following the administration of contrast agent; arterial, venous, and delayed phases were scanned at 25-30 seconds, 50-60 seconds, and 5 minutes, respectively. CT scanning was obtained at a slice thickness of 2 $\mathrm{mm}, 1.375$ pitch, $4 \times 2 \mathrm{~mm}$ collimation, 0.75 second gantry rotation time, $120 \mathrm{kV}$ and $100-180 \mathrm{mAs}$. The raw MDCT data were reconstructed with a workstation (Aquarius, TeraRecon Inc., San Mateo, CA, USA) and processed to obtain multiplanar reconstruction images. CT scan revealed duplication of right renal artery (Figure 1) and retroaortic left renal vein variation (Figure 2).

*This study has been presented as a poster at the 16th National Congress of Anatomy in Malatya, Turkey in 2014. 


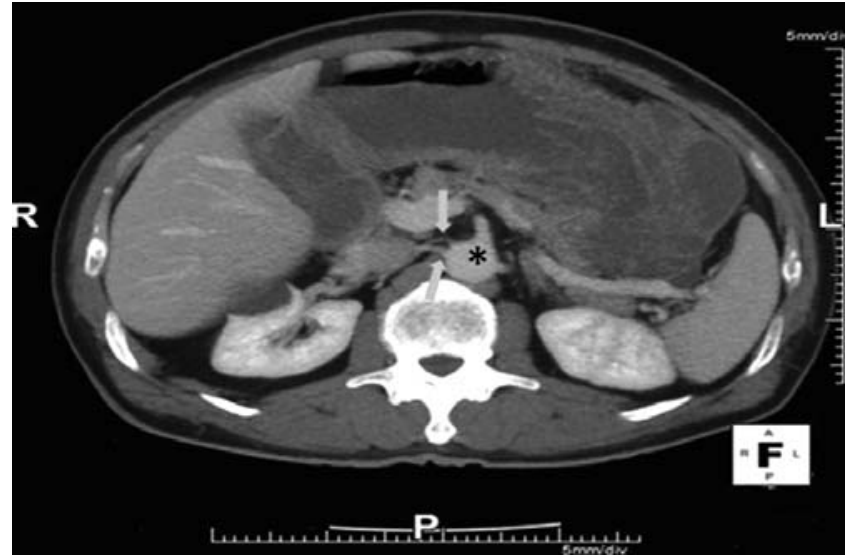

Figure 1. Duplicated right renal arteries (arrows). *: Abdominal aorta.

\section{Discussion}

Variations of the renal artery are related to the embryological development of vessels from the lateral mesonephric branches of the dorsal aorta. ${ }^{[3]}$ During the seventh week of embryological development, subcardinal veins develop and the anastomosis between the subcardinal veins forms the left renal vein. Unusual persistence or regression of the anastomoses at this level result in the formation of left renal variations, such as retroaortic left renal vein. ${ }^{[4,5]}$ Retroaortic left renal vein generally occurs without an accompanying anomaly. ${ }^{[6]}$

Accessory renal artery is a frequently encountered variation which occurs in $20-30 \%$ of the population. ${ }^{[7]}$ It may not be clinically significant when it is without any accompanying variation. However, when it occurs with other variations, the incidence in population is lower and

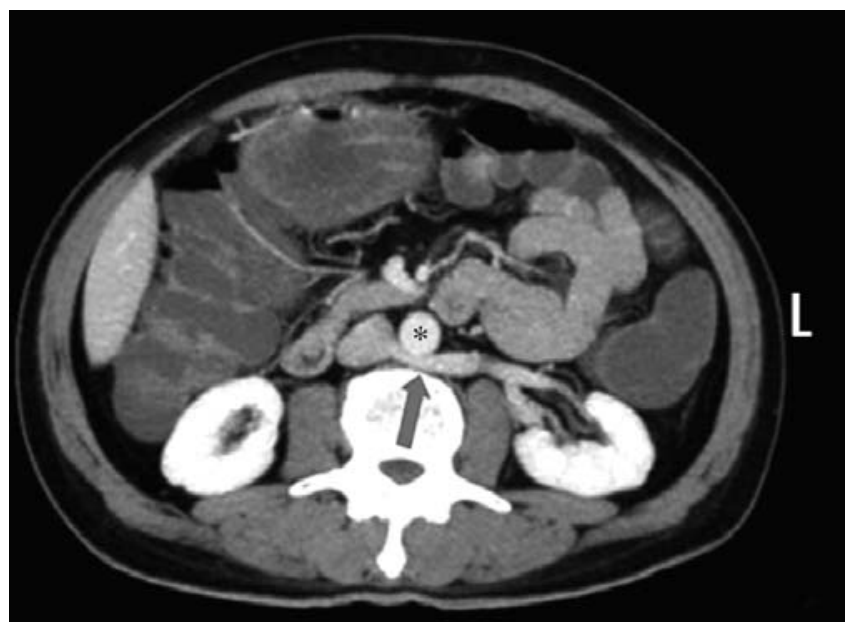

Figure 2. Axial CT image shows a retro-aortic left renal vein (arrow). *: Abdominal aorta. there is a greater probability that the variations will result in pathological conditions.

Clinicians should have a good knowledge of variations of renal arteries as these are important in microvascular surgery, renal transplantation and pathogenesis of hydronephrosis. ${ }^{[8]}$ Since accessory renal arteries are end arteries, ligation or ischemia of these may result in ischemia of the kidney segment it supplies. ${ }^{[9]}$ Double renal artery increases the risk of hemorrhage during renal transplantations, segmental ischemia and postoperative hemorrhage. Rate of transplant failures are more frequently seen in kidneys with double renal arteries. $^{[8,10]}$ Therefore, knowledge of the arterial variations and taking proper precautions is important for protecting the organ or tissue against ischemia. High incidence of vascular variations was reported in a study of cadaveric kidney donors and the authors emphasize the importance of recognizing variations in order to avoid injury during dissections. ${ }^{[1]]}$ Renal artery duplications may coexist with other urovascular variations such as renal vein duplications, ureter duplications, kidney anomalies and variations of genital artery. ${ }^{[7]}$ One study reported a higher incidence of accessory renal artery on the left side compared to the right side; ${ }^{[9]}$ conversely, other studies reported that its incidence was higher on the right side.$^{[10,12]}$ The variation was on the right side in our case.

Singh et al. ${ }^{[13]}$ reported that retroaortic left renal vein incidence was $2.4 \%$ in a series of 86 adult cadavers. Boyaci et al. ${ }^{[14]}$ found retroaortic left renal vein incidence as $7.4 \%$ in a retrospective study of CT images from 746 patients. The fact that their series excluded healthy population may account for the high incidence rate of the retroaortic left renal vein. However, retroaortic left renal vein incidence was reported as $2 \%$ in a study of CT and MR examinations from 2189 patients. ${ }^{[15]}$

While retroaortic left renal vein is usually asymptomatic, it can cause hematuria, flank pain and vascular dilatations. ${ }^{[16]}$ It can be associated with abdominal aort aneurysm which may be ruptured into the retroaortic left renal vein forming an aorto-left vein fistula and causing numerous clinical findings. ${ }^{[4,17,18]}$ It is reported that $94 \%$ of patients with this type fistulas had retroaortic left renal vein. ${ }^{[18]}$ Arslan et al. ${ }^{[19]}$ investigated the etiological role of retroaortic left renal vein in the development of varicocele and found varicocele in $77 \%$ of patients with retroaortic left renal vein, which suggests its possible role. Renal cysts and nephrolithiasis were the most frequently diagnosed conditions in patients with renal vascular variations, and these were considered to be due to negative effects of variations on renal function and hemodynamics. ${ }^{[14]}$ 
Since retroaortic renal vein can be confused with retroperitoneal lymph nodes, differential diagnosis requires greater care in patients with renal neoplasms as in our case. ${ }^{[20]}$ It is important to be aware of renal vein anomalies in retroperitoneal surgery, since failing to recognize these during surgery can result in bleeding, nephrectomy, and even death. ${ }^{[21]}$

A variation of right renal artery duplication with retroaortic left renal vein is rare. Knowledge of variations accompanied by pathologies as in our case may be important because it can affect diagnostic and treatment procedures.

\section{References}

1. Moore KL, Dalley AF. Clinically oriented anatomy. 4th ed. Philadelphia: Williams and Wilkins; 1999.

2. Fernandes RMP, Conte FHP, Favorito LA, Abidu-Figueiredo M, Babinski MA. Triple right renal vein: An uncommon variation. Int J Morphol 2005;23:231-3.

3. Shashikala P, Anjali W, Anshuman N, Jayshree D. A case report: double renal arteries. International Journal of Anatomical Variations 2012;5:22-4.

4. Balduyck B, Van Den Brande F, Rutsaert R. Abdominal aortic aneurysm rupture into a retro-aortic left renal vein. Acta Chir Belg 2014;114:136-8.

5. Sadler TW. Langman's medical embryology. 8th ed. Philadelphia: Lippincott Williams and Wilkins; 2000.

6. Gay SB, Armistead JP, Weber ME, Williamson BR. Left infrarenal region: anatomic variants, pathologic conditions, and diagnostic pitfalls. RadioGraphics 1991;11:549-70.

7. Mir NS, Ul Hassan A, Rangrez R, Hamid S, Sabia, Tabish SA, Iqbal, Suhaila, Masarat, Rasool Z. Bilateral duplication of renal vessels: anatomical, medical and surgical perspective. Int J Health Sci (Qassim) 2008;2:179-85.

8. Aristotle S, Sundarapandian, Felicia C. Anatomical study of variations in the blood supply of kidneys. J Clin Diagn Res 2013;7:15557.
9. Satyapal KS, Haffejee AA, Singh B, Ramsaroop L, Robbs JV, Kalideen JM. Additional renal arteries: incidence and morphometry. Surg Radiol Anat 2001;23:33-8.

10. Bordei P, Şapte E, Iliescu D. Double renal arteries originating from the aorta. Surg Radiol Anat 2004;26:474-9.

11. Costa HC, Moreira RJ, Fukunaga P, Fernandes RC, Boni RC, Matos AC. Anatomic variations in vascular and collecting systems of kidneys from deceased donors. Transplant Proc 2011;43:61-3.

12. Ozkan U, Oguzkurt L, Tercan F, Kizilkilic O, Koc Z, Koca N. Renal artery origins and variations: angiographic evaluation of 855 consecutive patients. Diagn Interv Radiol 2006;12:183-6.

13. Singh K, Gupta V, Sharma A. An embryological correlation with the incidence of retro aortic left renal vein. J Anat Soc India 2011;60: 190-2.

14. Boyaci N, Karakas E, Dokumaci DS, Yildiz S, Cece H. Evaluation of left renal vein and inferior vena cava variations through routine abdominal multi-slice computed tomography. Folia Morphol (Warsz) 2014;73:159-63.

15. Sahin C, Kacira OK, Tuney D. The retroaortic left renal vein abnormalities in cross-sectional imaging. Folia Med (Plovdiv) 2014;56:3842 .

16. Nam JK, Park SW, Lee SD, Chung MK. The clinical significance of a retroaortic left renal vein. Korean J Urol 2010;51:276-80.

17. Stefanczyk L, Majos M, Majos A, Polguj M. Duplication of the inferior vena cava and retroaortic left renal vein in a patient with large abdominal aortic aneurysm. Vasc Med 2014;19:144-5.

18. Tanaka H, Naito K, Murayama J, Ohteki H. Aorto-left renal vein fistula caused by a ruptured abdominal aortic aneurysm. Ann Vasc Dis 2013;6:738-40.

19. Arslan H, Etlik Ö, Ceylan K, Temizoz O, Harman M, Kavan M. Incidence of retro-aortic left renal vein and its relationship with varicocele. Eur Radiol 2005;15:1717-20.

20. Turner RJ, Young SW, Castellino RA. Dynamic continuous computed tomography: study of retroaortic left renal vein. J Comput Assist Tomogr 1980;4:109-11.

21. Karkos CD, Bruce IA, Thomson GJ, Lambert ME. Retroaortic left renal vein and its implications in abdominal aortic surgery. Ann Vasc Surg 2001;15:703-8.

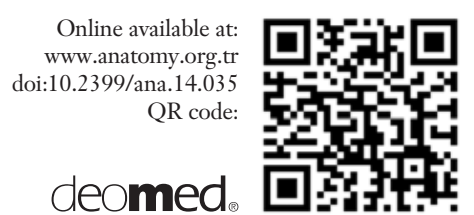

Correspondence to: Ozan Turamanlar, MD

Department of Anatomy, Faculty of Medicine, Afyon Kocatepe University, Afyonkarahisar, Turkey

Phone: +90 2724440303

e-mail: ozanturamanlar@hotmail.com

Conflict of interest statement: No conflicts declared.

This is an open access article distributed under the terms of the Creative Commons Attribution-NonCommercial-NoDerivs 3.0 Unported (CC BY-NCND3.0) Licence (http://creativecommons.org/licenses/by-nc-nd/3.0/) which permits unrestricted noncommercial use, distribution, and reproduction in any medium, provided the original work is properly cited. Please cite this article as: Turamanlar O, Ünlü E, Toktaş M, Horata E, Songur A. Variation of right renal artery duplication with retroaortic left renal vein: a case report. Anatomy 2015;9(2):91-93. 